\title{
Microwave-assisted addition of azomethines to isatoic anhydride
}

\author{
E DOMINIC JACOB, ${ }^{\mathrm{a}, *}$ LOPEZ MATHEW $^{\mathrm{b}}$ and BABY THOMAS ${ }^{\mathrm{c}}$ \\ ${ }^{a}$ Department of Chemistry, Research Centre, Nirmala College, Muvattupuzha 686661 \\ ${ }^{\mathrm{b}}$ Department of Chemistry, Union Christian College, Aluva 683102 \\ ${ }^{\mathrm{c}}$ Department of Chemistry, St. Dominics College, Kanjrapally 686512 \\ e-mail: ejdominic@rediffmail.com
}

MS received 21 August 2006; revised 30 January 2007

\begin{abstract}
Diels-Alder addition of azomethines to isatoic anhydride in a solvent-free and eco-friendly condition is investigated using a microwave oven. The product is exclusively 2,3-diaryl-2,3-dihydroquinazolin-4(1H)-ones 4a-d. HOMO-LUMO energy of the iminoketene and the dienophiles were calculated using semi-empirical AM1 calculations.
\end{abstract}

Keywords. Microwave-assisted additions; solvent-free reaction; synthesis; dihydroquinazolinones; AM1 calculations.

\section{Introduction}

Chemical reactions brought about by microwave irradiation gathered momentum in recent years. ${ }^{1-8}$ The elegance of the reaction, high yield, short time span, simplified work-up procedure and eco-friendly conditions are the main advantages of the method. Although microwave reactions were begun in domestic microwave ovens, they are conducted in more sophisticated chemical microwave ovens now-a-days. ${ }^{9}$ The existence of 'hot spots', inhomogeneity of the microwave field in the region to be heated the handicap in measuring the temperature of reaction, possibility of explosion, are some of the main defects of microwave oven reactions. ${ }^{10}$ However, rotating the reaction platform that averages the field can decrease the inhomogeneity of the field. The temperature can be measured by taking out the sample at interval as required. The reproducibility of the result was also checked by repeating the experiment several times. We used the domestic version, as we are unable to use chemical ovens at present. Many quinazolinones, which are well known as choleretic and antidiabetic agents, ${ }^{11}$ were prepared by treating anthranilic acid ${ }^{12-15}$ with thionyl chloride in dry benzene.

*For correspondence

\section{Experimental section}

Isatoic anhydride was purchased from Aldrich and used as received. Azomethines were prepared according to literature procedure, purified by column chromatography and recrystallised from methanol before application. ${ }^{16}$ IR spectra were recorded on a Bomem MB Serier FT-IR spectrophotometer and absorbencies are reported in $\mathrm{cm}^{-1}$. The NMR spectra were recorded in Bruker $300 \mathrm{MHz}$ FT-NMR spectrometer on samples dissolved in $\mathrm{CDCl}_{3}$ and chemical shifts are reported in $\delta(\mathrm{ppm})$ relative to $\mathrm{Me}_{4} \mathrm{Si}$ as internal standard. Mass spectra were obtained by EIMS technique at $70 \mathrm{eV}$ on an AutoSpec mass spectrometer. CHN analyses were carried out using Elementar Vario EL III. Melting points were recorded on Mel-Temp II Laboratory Devices, USA and are uncorrected. All reactions were monitored by thin layer chromatography (TLC); All TLC were carried out on Alugram SIL G/K plates. Visualization was effected with a UV lamp.

Microwave oven reactions were performed on a Kenstar domestic, multimode, without on and off mode, microwave oven, with rotating platform tray, with a power source of $230 \mathrm{~V}, 50 \mathrm{~Hz}$, and microwave energy output $800 \mathrm{~W}$, microwave input power $1200 \mathrm{~W}$ and microwave frequency $2450 \mathrm{MHz}$.

A mixture of isatoic anhydride 1 (593.3 mg, $3.64 \mathrm{mmol})$ and azomethine $3 \mathbf{a}-\mathbf{d}(3.64 \mathrm{mmol})$ were ground together in a mortar and transferred into a $50 \mathrm{~mL}$ beaker. The reaction mixture was then micro- 
wave-irradiated without solvent for $2 \mathrm{~min}$ at a temperature of $60^{\circ} \mathrm{C}$. After cooling to room temperature, the reaction mixture was extracted with dichloromethane $(20 \mathrm{~mL})$, filtered to remove all unreacted and insoluble materials. The clear solution was concentrated and cooled. The 2,3-diaryl-2,3-dihydroquinazolin-4(1H)-ones $\mathbf{4 a - d}$ recrystallised from $2: 1$ petroleum ether dichloromethane mixture. The structure of $\mathbf{4 a - d}$ was confirmed based on spectral data.

The temperature of the reaction mixture at the time of reaction was measured by microwave irradiation of the same mass of reactants taken in a Borosil open test tube of $7.0 \mathrm{~cm}$ length, $0.9 \mathrm{~cm}$ diameter and $3.5 \mathrm{~mL}$ capacity. The test tube was kept in a $100 \mathrm{~mL}$ beaker and then microwave-irradiated for $2 \mathrm{~min}$. The test tube was taken out, the temperature of the molten material was noted immediately with a thermometer and found to be $60^{\circ} \mathrm{C}$.

Spectral data for (4a)-2,3-diphenyl-2,3-dihydroquinazolin-4(1H)-one:

IR $\left(\mathrm{KBr}, \mathrm{cm}^{-1}\right)$ : 3299 (NH stretch), $1640(\mathrm{C}=\mathrm{O}$ stretch), 1512, 1485, 1391, 1310, 1256, 1162, 1034, 872, 751, 703, 629, 548.

Anal. Calcd for $\mathrm{C}_{20} \mathrm{H}_{16} \mathrm{~N}_{2} \mathrm{O}$ : C, 80.00; H, 5.33; N, 9.33; O, 5.33\%. Found: C, 80.02; H, 5.32; N, 9.35; $\mathrm{O}, 5 \cdot 31 \%$.

Spectral data for (4b)-3-(4-chlorophenyl)-2-phenyl-2,3-dihydroquinazolin-4(1H)-one:

IR $\left(\mathrm{KBr}, \mathrm{cm}^{-1}\right): 3305.51$ (NH stretch), 1638.79 (C=O stretch), 1513, 1245.79, 1164.5, 1095.73, 1020·87, 833.591, 764.825, 702·399.
Anal. Calcd for $\mathrm{C}_{20} \mathrm{H}_{15} \mathrm{ClN}_{2} \mathrm{O}$ : C, 71.85; H, 4.49; Cl, 10.48; N, 8.38; O, 4.79\%. Found: C, 71.87; H, 4.48; Cl, 10.48; N, 8.39; O, 4.78\%.

Spectral data for (4c)-3-(4-methylphenyl)-2-phenyl-2,3-dihydroquinazolin-4(1H)-one:

IR $\left(\mathrm{KBr}, \mathrm{cm}^{-1}\right)$ : $3305 \cdot 75$ (NH stretch), 1638.79 (C=O stretch), 1507.84, 1395.42, 1314.22, 1251.79, 1152.00, 1020·87, 821·154, 758.728, 696.302.

Anal. Calcd for $\mathrm{C}_{21} \mathrm{H}_{18} \mathrm{~N}_{2} \mathrm{O}$ : C, 80.25; H, 5.73; N, 8.92; O, 5.10\%. Found: C, 80.27; H, 5.74; N, 8.90; O, $5 \cdot 09 \%$.

Spectral data for (4d)-3-(2-methoxyphenyl)-2phenyl 2,3-dihydroquinazolin-4(1H)-one:

IR $\left(\mathrm{KBr}, \mathrm{cm}^{-1}\right): 3293$ ( $\mathrm{NH}$ stretch), $1635(\mathrm{C}=\mathrm{O}$ stretch), 1510, 1483, 1398, 1312, 1272, 1166, 1034, 764, 711.

Anal. Calcd for $\mathrm{C}_{21} \mathrm{H}_{18} \mathrm{~N}_{2} \mathrm{O}_{2}$ : C, 76.37; $\mathrm{H}, 5.45 ; \mathrm{N}$, 8.48; O, 9.7\%. Found: C, 76.38; H, 5.44; N, 8.50; O, $9 \cdot 68 \%$.

\section{Results and discussion}

In the present studies we have found that in the absence of solvents and in time intervals of less than 3 min equimolar mixtures of isatoic anhydride ${ }^{17-21}$ and azomethines react readily under microwave irradiation to give 2,3-diaryl-2,3-dihydroquinazolin$4(1 \mathrm{H})$-ones $\mathbf{4 a - d}$, as shown in scheme 1 with yields of 71 to $90 \%$.

The $8 \pi$ component of the unisolable heterodiene combines with the $2 \pi$ component of heterodienophile

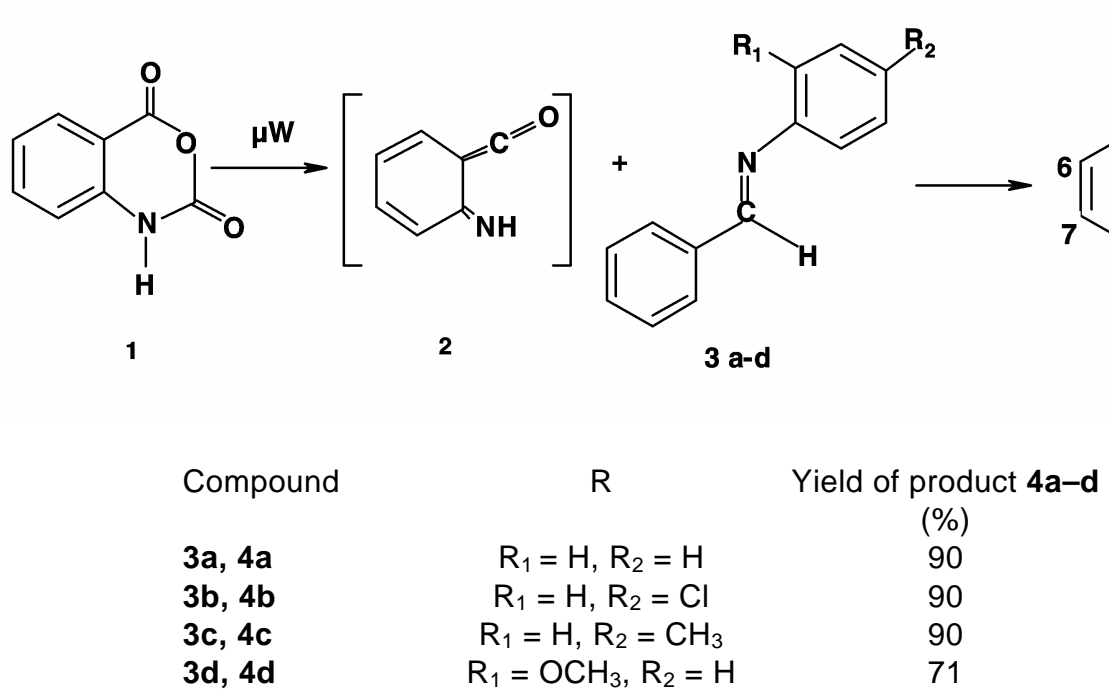

Scheme 1. 
Table 1. Characterization data of compounds $\mathbf{4 a - d}$.

\begin{tabular}{|c|c|c|c|c|c|}
\hline $\begin{array}{l}\text { Compd. } \\
\text { (colour) }\end{array}$ & $\begin{array}{l}\text { m.p. } \\
\left({ }^{\circ} \mathrm{C}\right)\end{array}$ & $\begin{array}{l}\text { Yield } \\
(\%)\end{array}$ & ${ }^{1} \mathrm{H}$ NMR $(\delta, \mathrm{ppm})$ & ${ }^{13} \mathrm{C}$ NMR $(\delta, \mathrm{ppm})$ & MS m/z (\%) \\
\hline $\begin{array}{l}\mathbf{4 a} \\
\text { (Cream) }\end{array}$ & 210 & 90 & $\begin{array}{l}7 \cdot 99(d, 1 \mathrm{H}, J=8 \cdot 2 \mathrm{~Hz}), 7 \cdot 97 \\
(t, 1 \mathrm{H}, J=7 \cdot 1 \mathrm{~Hz}), 7 \cdot 33(d, 1 \mathrm{H}, \\
J=8 \cdot 3 \mathrm{~Hz}), 7 \cdot 30-7 \cdot 21(m, 5 \mathrm{H}) \\
7 \cdot 14-7 \cdot 01(m, 5 \mathrm{H})), 6 \cdot 86(t, 1 \mathrm{H}, \\
J=7 \cdot 0 \mathrm{~Hz}), 6 \cdot 07(s, 1 \mathrm{H}), 4 \cdot 73 \\
\text { (s, broad, } 1 \mathrm{H}, \mathrm{D}_{2} \mathrm{O} \text { exchangeable) }\end{array}$ & 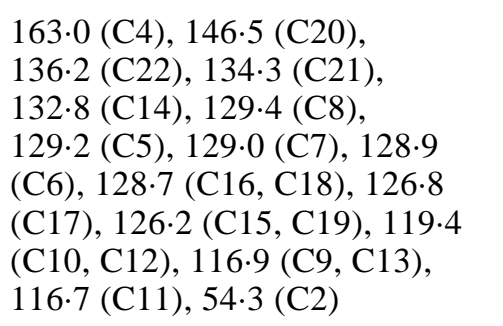 & $\begin{array}{l}300\left(M^{+}, 18\right), \\
223(50), 209 \\
(15), 208 \\
(100), 77(20)\end{array}$ \\
\hline $\begin{array}{l}\mathbf{4 b} \\
\text { (Cream) }\end{array}$ & 221 & 90 & $\begin{array}{l}7 \cdot 99(d, 1 \mathrm{H}, J=8 \cdot 2 \mathrm{~Hz}), 7 \cdot 97 \\
(t, 1 \mathrm{H}, J=7 \cdot 1 \mathrm{~Hz}), 7 \cdot 33(d, 1 \mathrm{H}, \\
J=8 \cdot 3 \mathrm{~Hz}), 7 \cdot 25(d, 2 \mathrm{H}, \\
J=8 \cdot 0 \mathrm{~Hz}), 723(d, 2 \mathrm{H}, J=8 \\
0 \mathrm{~Hz}), 7 \cdot 14-7 \cdot 01(m, 5 \mathrm{H}), 6 \cdot 87(t, \\
1 \mathrm{H}, J=7 \cdot 0 \mathrm{~Hz}), 6 \cdot 06(s, 1 \mathrm{H}), 4 \cdot 59 \\
\text { (s, broad, } 1 \mathrm{H}, \mathrm{D}_{2} \mathrm{O} \text { exchangeable) }\end{array}$ & $\begin{array}{l}164 \cdot 5 \text { (C4), } 133 \cdot 9 \text { (C20), 130·3 } \\
(\mathrm{C} 22), 129 \cdot 1(\mathrm{C} 21) 129 \cdot 0(\mathrm{C} 14), \\
128 \cdot 9(\mathrm{C} 17), 128 \cdot 7(\mathrm{C} 8), 128 \cdot 3 \\
(\mathrm{C} 5), 128 \cdot 1(\mathrm{C} 7), 127 \cdot 2 \mathrm{C} 6), \\
126 \cdot 7(\mathrm{C} 16, \mathrm{C} 18), 119 \cdot 7(\mathrm{C} 15, \\
\mathrm{C} 19), 114 \cdot 7(\mathrm{C} 10, \mathrm{C} 12), 113 \cdot 6 \\
(\mathrm{C} 9, \mathrm{C} 13), 113 \cdot 5(\mathrm{C} 11), 54 \cdot 3 \\
(\mathrm{C} 2)\end{array}$ & $\begin{array}{l}334\left(M^{+}, 12\right) \\
336(4), 257 \\
(34), 209 \\
(48), 208 \\
(100), 77(12)\end{array}$ \\
\hline $\begin{array}{l}\mathbf{4 c} \\
\text { (Pale } \\
\text { yellow) }\end{array}$ & 188 & 90 & $\begin{array}{l}8 \cdot 00(d, 1 \mathrm{H}, J=8 \cdot 2 \mathrm{~Hz}), 7 \cdot 97 \\
(t, 1 \mathrm{H}, J=7 \cdot 1 \mathrm{~Hz}), 7 \cdot 33(d, 1 \mathrm{H}, \\
J=8 \cdot 3 \mathrm{~Hz}), 7 \cdot 27(d, 2 \mathrm{H}, \\
J=8 \cdot 0 \mathrm{~Hz}), 7 \cdot 14-7 \cdot 01(\mathrm{~m}, 5 \mathrm{H}), \\
6 \cdot 86(t, 1 \mathrm{H}, J=7 \cdot 0 \mathrm{~Hz}), 6 \cdot 61 \\
(d, 2 \mathrm{H}, J=9 \cdot 0 \mathrm{~Hz}), 6 \cdot 04(s, 1 \mathrm{H}), \\
4 \cdot 63\left(s, \text { broad, } 1 \mathrm{H}, \mathrm{D}_{2} \mathrm{O}\right. \\
\text { exchangeable }), 2 \cdot 26\left(\mathrm{~s}, 3 \mathrm{H}, \mathrm{CH}_{3}\right)\end{array}$ & $\begin{array}{l}163 \cdot 0 \text { (C4), } 145 \cdot 3(\mathrm{C} 20), 140 \cdot 1 \\
(\mathrm{C} 22), 138 \cdot 0(\mathrm{C} 21), 136 \cdot 4(\mathrm{C} 14), \\
133 \cdot 7(\mathrm{C} 17), 129 \cdot 5(\mathrm{C} 8), 129 \cdot 1 \\
(\mathrm{C} 5), 128 \cdot 9(\mathrm{C} 7), 128 \cdot 7(\mathrm{C} 6), \\
126 \cdot 9(\mathrm{C} 16, \mathrm{C} 18), 126 \cdot 8(\mathrm{C} 15, \\
\mathrm{C} 19), 119 \cdot 5(\mathrm{C} 10, \mathrm{C} 12), 116 \cdot 9 \\
(\mathrm{C} 9, \mathrm{C} 13), 114 \cdot 7(\mathrm{C} 11), 54 \cdot 3 \\
(\mathrm{C} 2), 21 \cdot 1(\mathrm{Me} \text { at C17) }\end{array}$ & $\begin{array}{l}314\left(M^{+}, 15\right), \\
237(30), 209 \\
(15), 208 \\
(100), 77(20)\end{array}$ \\
\hline $\begin{array}{l}\text { 4d } \\
\text { (Cream) }\end{array}$ & 190 & 71 & $\begin{array}{l}8 \cdot 03(d, 1 \mathrm{H}, J=8 \cdot 2 \mathrm{~Hz}), 8 \cdot 00 \\
(t, 1 \mathrm{H}, J=7 \cdot 2 \mathrm{~Hz}), 7 \cdot 93(d, 1 \mathrm{H}, \\
J=8 \cdot 00 \mathrm{~Hz}), 7 \cdot 90(d, 1 \mathrm{H}, \\
J=8 \cdot 3 \mathrm{~Hz}), 7 \cdot 36(t, 1 \mathrm{H}, \\
J=7 \cdot 20 \mathrm{~Hz}), 7 \cdot 30(t, 1 \mathrm{H}, \\
J=7 \cdot 2 \mathrm{~Hz}), 7 \cdot 25-7 \cdot 15(\mathrm{~m}, 5 \mathrm{H}), \\
7 \cdot 05(t, 1 \mathrm{H}, J=7 \cdot 00 \mathrm{~Hz}), 6 \cdot 78(d, \\
1 \mathrm{H}, J=8 \cdot 00 \mathrm{~Hz}), 6 \cdot 19(s, 1 \mathrm{H}), 3 \cdot 77 \\
\left(s, 3 \mathrm{H}, \mathrm{CH}_{3}\right), 4 \cdot 58(s, \text { broad, } 1 \mathrm{H}, \\
\left.\mathrm{D}_{2} \mathrm{O} \text { exchangeable }\right)\end{array}$ & $\begin{array}{l}164 \cdot 5 \text { (C4), } 146 \cdot 5(\mathrm{C} 20), 140 \cdot 5 \\
(\mathrm{C} 19), 134 \cdot 4(\mathrm{C} 22), 132 \cdot 5(\mathrm{C} 21), \\
129 \cdot 7(\mathrm{C} 14), 129 \cdot 4(\mathrm{C} 8), 129 \cdot 2 \\
(\mathrm{C} 5), 129 \cdot 0(\mathrm{C} 7), 128 \cdot 2(\mathrm{C} 6), \\
127 \cdot 8(\mathrm{C} 15), 123 \cdot 6(\mathrm{C} 17), 121 \cdot 2 \\
(\mathrm{C} 16), 120 \cdot 5(\mathrm{C} 18), 117 \cdot 4(\mathrm{C} 10, \\
\mathrm{C} 12), 116 \cdot 7(\mathrm{C} 9, \mathrm{C} 13), 114 \cdot 5 \\
(\mathrm{C} 11), 57(\mathrm{Me} \text { of } \mathrm{MeO} \text { at C19), } \\
55 \cdot 7 \text { (C2) }\end{array}$ & $\begin{array}{l}330\left(M^{+}, 30\right), \\
253(33.8), \\
209(12.5), \\
208(100), 77 \\
(15)\end{array}$ \\
\hline
\end{tabular}

to form heterocyclic system. The polar nature of the dienophile facilitates the reaction exclusively in a way that the negative site is connected to the ketene part of the diene and positive site to the imino part. It has been found that the yield of the product $\mathbf{4 a - c}$ is almost constant irrespective of the various substituents on the azomethine part. Therefore, the effect of the substituent on the dienophile part is insignificant. A very interesting observation is that azomethine addition is completely regiospecific in which the nitrogen is oriented towards the ketene part.

The results are presented in table 1 .

The HOMO-LUMO energies of $\mathbf{2}$ and 3a-d have been calculated using the semiempirical AM1 theory. These values are tabulated in table 2. Inspection of the data given in table 2 reveals that the energy difference between the HOMO of diene and the LUMO of dienophile is smaller than that of the difference between the LUMO of the diene and the HOMO of the dienophile. Therefore it is concluded that the reaction between iminoketene and azomethine takes place via the interaction of HOMO of the former with the LUMO of the latter.

Electron-withdrawing chlorine lowers LUMO energy whereas electron-donating $-\mathrm{CH}_{3}$ and $-\mathrm{OCH}_{3}$ groups increase LUMO energy, the effect being more pronounced for the $-\mathrm{OCH}_{3}$ group. However, the HOMO-LUMO energy difference is nearly constant lending support to the conclusion that substituents have only minimal effect on the reaction. 
Table 2. HOMO and LUMO energies in hartrees.

\begin{tabular}{|c|c|c|c|c|}
\hline Structure & HOMO & LUMO & $\begin{array}{c}\text { HOMO(2)-LUMO } \\
\text { (3a-d) }\end{array}$ & $\begin{array}{c}\text { LUMO (2)-HOMO } \\
\text { (3a-d) }\end{array}$ \\
\hline 2 & $-0 \cdot 31039$ & -0.02545 & & \\
\hline $3 a$ & $-0 \cdot 32700$ & $-0 \cdot 01844$ & $0 \cdot 29195$ & $0 \cdot 30155$ \\
\hline $3 \mathbf{b}$ & $-0 \cdot 32849$ & -0.02554 & $0 \cdot 28485$ & $0 \cdot 30304$ \\
\hline $3 c$ & $-0 \cdot 32109$ & -0.01817 & $0 \cdot 2922$ & $0 \cdot 29564$ \\
\hline $3 d$ & $-0 \cdot 31624$ & -0.01394 & $0 \cdot 2965$ & $0 \cdot 34169$ \\
\hline
\end{tabular}

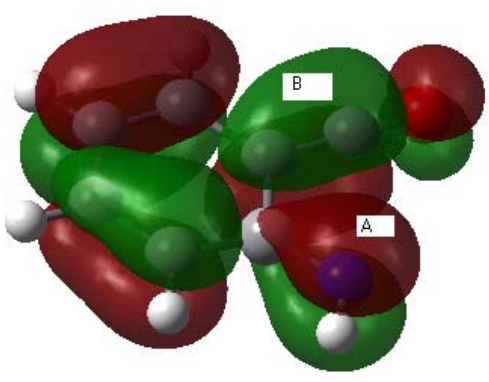

2 HOMO

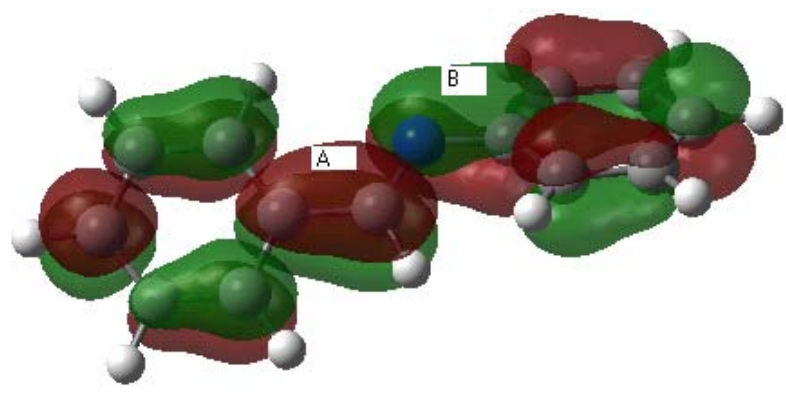

3a LUMO

Figure 1. Lobes marked A and B on 2 interact with lobes marked A and B in 3a respectively.<smiles>O=C1C=CC=CC1=NOc1ccccc1</smiles>

2 HOMO

Figure 2. Only the relevant portions of orbitals are shown for clarity.

The HOMO of 2 and LUMO of 3a are given in figure 1. A schematic sketch of the HOMO-LUMO interaction is given in figure 2. The orbital on the ketene carbon is in phase with the LUMO on the $\mathrm{N}$ of the dienophile, while the orbital on the imino part of the diene is in phase with the orbital on the carbon on the dienophile. Thus the reaction proceeds exclusively in the indicated direction.

\section{Conclusion}

The in situ generation of diene from isatoic anhydride followed by Diels-Alder addition of azomethines is

a novel microwave-assisted reaction. It is an elegant method of synthesis in a short time duration, with good yield and maximum atom efficiency. The work up of the reaction mixture is also very simple. The compounds $\mathbf{4 a - d}$ were unambiguously identified by clear spectral data and elemental analyses.

\section{Acknowledgement}

The authors are thankful to The Director, Indian Institute of Chemical Technology, Hyderabad for providing mass spectral facilities. The authors are also thankful to Ms Ceenamma Jacob, Dr Varghese John, Ms Roshni Mathew Maliakkal, Mr Cherian K George, for providing encouragement and help and to the University Grants Commission, New Delhi for financial support.

\section{References}

1. Bogdal D, Lukasiewicz M, Pielichowski J, Miciale A and Bednarz Sz 2003 Tetrahedron 59649

2. Leadbeater N E 2005 J. Chem. Soc., Chem. Commun. 2881

3. Dominic E J and Lopez M 2004 Curr. Sci. 861368

4. Bari S S, Bose A K, Chaudhary A G, Manhas M S, Raju V S and Robb E W 1992 J. Chem. Educ. 69938

5. Shui-Tein Chen, Shyh-Horng Chiou and Kung-Tsung Wang 1990 J. Chem. Soc. Chem., Commun. 807 
6. Gedye R N, Smith F E and Westaway K C 1988 Can. J. Chem. 6617

7. Gedye R N, Rank W and Westaway K C 1991 Can. J. Chem. 69706

8. Giguere R J, Bary T L and Duncan S M 1986 Tetrahedron Lett. 274945

9. Brittany L H 2002 Microwave synthesis: Chemistry at the speed of light (New York: CEM Publishing)

10. Loupy A 2002 Microwave in organic synthesis (Weinheim: Wiley-VCH)

11. Koizumi M 1977 Japan Kokai 77,07,978 Chem. Abst. $8753366 b$

12. Kametani T, Loc C V, Higa T, Koizumi M, Ihara M and Fukumoto K 1977 J. Am. Chem. Soc. 992306

13. Kametani T, Loc C V, Higa T, Koizumi M, Ihara M and Fukumoto K 1977 J. Chem. Soc., Perkin Trans I 212347

14. Kametani T, Higa T, Loc C V, Ihara M, Koizumi M and Fukumoto K 1976 J. Am. Chem. Soc. 986186
15. Garin J, Merino P, Orduna J, Tejero T and Uriel S 1991 Tetrahedron Lett. 323263

16. (a) Furniss B S, Hannaford A J, Rogers V, Smith P W $G$ and Tatchell A R 1980 In Vogel's textbook of practical organic chemistry 4th edn (London: ELBS) p. 672; (b) Baliah V and Chandrasekharan V 1970 Indian J. Chem. 8 1096; (c) Tanaka M and Kobayasha T 1985 Synthesis 10 967; (d) Kiss P Aushas 1948 Acta Phys. Chem. 28386

17. Crabtree H E, Smalley R K and Suschitzky H $1968 \mathrm{~J}$. Chem. Soc $(C) 2730$

18. Rao V B and Ratnam C V 1979 Indian J. Chem. B18 409

19. Reddy C H K, Reddy P S N and Ratnam C V 1987 Indian J. Chem. B26 882

20. Steiger R P and Wagner E C 1953 J. Org. Chem. 18 1427

21. Archer J A, Barker A J and Smalley R K 1973 J. Chem. Soc., Perkin Trans I 1169 